\title{
The preparation process and feature of the topological insulator $\mathrm{Bi}_{2} \mathrm{Te}_{3}$
}

\author{
Peng Chen · Dajin Zhou • Pingyuan Li • \\ Yajing Cui $\cdot$ Yongliang Chen
}

Received: 31 October 2013/Revised: 16 January 2014/ Accepted: 18 January 2014/Published online: 9 February 2014

(C) The Author(s) 2014. This article is published with open access at Springerlink.com

\begin{abstract}
Topological insulators are insulating in the bulk but have metallic surface states. Its unique physicochemical properties can find numerous applications in electronics, spintronics, photonics, the energy sciences, and the signal control of transportation. We report an experimental approach to synthesize the high-quality single crystal of topological insulator $\mathrm{Bi}_{2} \mathrm{Te}_{3}$ by using self-flux method. We obtained the optimal preparation conditions by adjusting the parameters of heat treatment, and successfully prepared the single-crystal $\mathrm{Bi}_{2} \mathrm{Te}_{3}$ sample. The as-grown samples have a surface with bright metallic luster and are soft and fragile. Furthermore, $\mathrm{Bi}_{2} \mathrm{Te}_{3}$ has the obvious layer structure from SEM results. The data of $\mathrm{X}$-ray diffraction and scanning electron microscope show that $\mathrm{Bi}_{2} \mathrm{Te}_{3}$ single crystal grows along the $c$-axis with the order of $\mathrm{Te}^{(1)}-\mathrm{Bi}-$ $\mathrm{Te}^{(2)}-\mathrm{Bi}-\mathrm{Te}^{(1)}$ and crystallizes in the hexagonal system with space group of $\mathrm{R} / 3 \mathrm{~m}$. The $\rho-T$ curve shows that $\rho$ decreases with temperature, showing metallic behavior over the whole temperature range.
\end{abstract}

Keywords $\mathrm{Bi}_{2} \mathrm{Te}_{3} \cdot$ Single crystal $\cdot$ Topological insulator

\section{Introduction}

Topological insulators (TIs) are a new class of quantum states of matter with topologically protected conducting

P. Chen · D. Zhou · P. Li · Y. Cui · Y. Chen $(\square)$

Key Laboratory of Magnetic Levitation Technologies and Maglev Trains, Ministry of Education of China, and

Superconductivity and New Energy R\&D Center, Southwest

Jiaotong University, Chengdu 610031, China

e-mail: 1lchen@home.swjtu.edu.cn surface states, arising from the topology of the bulk electronic band structure [1-3]. They are insulating in the bulk but possess metallic surface states protected by timereversal symmetry [4]. The surface structure is composed of single Dirac cones, and belongs to the Dirac particles system [5]. The carrier can be transmitted in the surface without scattering and energy loss. The topological surface states are gapless, and ambipolar conduction in the gate voltage tuned devices is taken as a signature of TI surface transport [6]. Because of these features, TI materials have great application prospects in the field of transistors, storage devices, magnetic sensors, and energy efficient products. Three-dimensional TIs including $\mathrm{Sb}_{2} \mathrm{Te}_{3}, \mathrm{Bi}_{2} \mathrm{Se}_{3}$, and $\mathrm{Bi}_{2} \mathrm{Te}_{3}$ are also excellent thermoelectrics, which have been intensively investigated for optimized thermoelectric performance in the recent decades [7, 8]. The theories and experiments have successively confirmed that they have large bulk band gap and single Dirac cone surface states [9-12]. They have quickly become a hot spot in the study of topological insulator material. The topological characteristic of $\mathrm{Bi}_{2} \mathrm{Te}_{3}$ was predicted by first-principles calculation and analysis of the model in Ref. [10] and observed by the angle-resolved photoemission spectroscopy (ARPES) [12, 13]. The Fermi surface (FS) is the shape of the snowflake-like. The $\mathrm{Bi}_{2} \mathrm{Te}_{3}$ single crystal was predicted to be a bulk insulator, and the electron carriers were observed in experiment to arise from crystal imperfections, specifically vacancies and defects [12]. It is found that increasing Se concentration effectively suppresses the bulk carrier transport and induces semiconducting behavior in $\mathrm{Bi}_{2}\left(\mathrm{Te}_{1-x} \mathrm{Se}_{x}\right)_{3}$. An ambipolar field effect from the gapless surface states was observed in $\mathrm{Bi}_{2}\left(\mathrm{Se}_{0.8} \mathrm{Te}_{0.2}\right)_{3}$ [14].

The single crystal along the $c$-axis with $\mathrm{Te}^{(1)}-\mathrm{Bi}-\mathrm{Te}^{(2)}$ $\mathrm{Bi}-\mathrm{Te}^{(1)}$ cycle stacked growth, belongs to the hexagonal 
system, and space group is $\mathrm{R} / 3 \mathrm{~m}$. Between $\mathrm{Te}$ and $\mathrm{Bi}$ layer is a covalent bond, and Van-der Waals bond between $\mathrm{Te}$ and $\mathrm{Te}$ layer. So the single $\mathrm{Bi}_{2} \mathrm{Te}_{3}$ is cleavage easily along the basal plane. Near the melting point temperature $\mathrm{Bi}_{2} \mathrm{Te}_{3}$ deviates from the strict ratio of chemical components. It presents a little excess $\mathrm{Bi}$ that $\mathrm{Bi}$ accounted for $40.065 \%$ of atomic weight ratio and $\mathrm{Te}$ accounted for $59.935 \%$ [15].

$\mathrm{Bi}_{2} \mathrm{Te}_{3}$ can greatly improve the speed of computer chips and efficiency. Using existing semiconductor technology, this kind of material can allow electrons to move on the surface without energy consumption at room temperature, so the application of this chip to modern transportation will lead to a leap.

Early by directional solidification method and the method of zone melting method prepared $\mathrm{Bi}_{2} \mathrm{Te}_{3}$ single crystal or columnar crystals; commercial production is also using these methods. $\mathrm{Bi}_{2} \mathrm{Te}_{3}$ as thermoelectric material was prepared by hot pressing method [16], the SPS (spark plasma sintering) method [17], hot extrusion method [18], solvent method [19], and so on. The samples with irregular polyhedron did not show the structural characteristics and contained an impurity phase [15]. Recently, the topological property of $\mathrm{Bi}_{2} \mathrm{Te}_{3}$ has been confirmed [12,13]. In order to better study the bizarre properties of the TIs, we need the high-quality single-crystal material. So we have done many times trials according to the structure characteristics of $\mathrm{Bi}_{2} \mathrm{Te}_{3}$ single crystal with the self-flux method. To try and improve the process of proportioning, sample preparation, sintering, testing, etc., we summarize an optimization method of preparation of $\mathrm{Bi}_{2} \mathrm{Te}_{3}$ single crystal of highquality material.

\section{Experimental}

High-purity elemental Bi (99.999\%) and Te (99.999 \%) were used for the $\mathrm{Bi}_{2} \mathrm{Te}_{3}$ crystal growth. $\mathrm{Bi}$ and $\mathrm{Te}$ mixed with a molar ratio of 2:3 were fully grinded in glove box filled with argon at least $2 \mathrm{~h}$, enclosed into evacuated quartz tubes, and then in heat treatment with the process of Fig. 1. We design three groups of $\mathrm{Bi}_{2} \mathrm{Te}_{3}$ samples (see Table 1). The first group (H-750-H-850) is to change the highest temperature in the range of $750-850{ }^{\circ} \mathrm{C}$, and keep heating time, quenching temperature, cooling rate unchanged; the second group (Q500-Q580) is to change quenching temperature from 500 to $580{ }^{\circ} \mathrm{C}$, and keep other conditions unchanged; the third group $(\mathrm{C}-4-\mathrm{C}-6)$ is only to change cooling rate.

The crystal structure was studied by powder X-ray diffraction (XRD) using an X'Pert MRD diffractometer with $\mathrm{Cu} K \alpha$ radiation. All observed reflections were indexed.

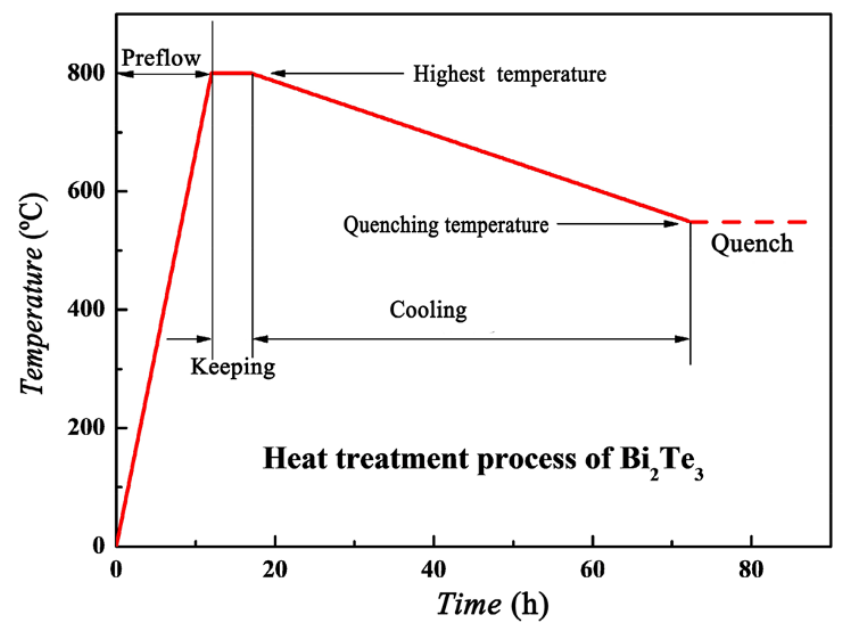

Fig. 1 Heat treatment process of $\mathrm{Bi}_{2} \mathrm{Te}_{3}$

Table 1 The grouped control variables in the heat treatment process ( $H$ highest, $Q$ Quenching, and $C$ Cooling)

\begin{tabular}{lllll}
\hline No. & $\begin{array}{l}\text { Highest } \\
\text { temperature } \\
\left({ }^{\circ} \mathrm{C}\right)\end{array}$ & $\begin{array}{l}\text { Keeping } \\
\text { time } \\
(\mathrm{h})\end{array}$ & $\begin{array}{l}\text { Quenching } \\
\text { temperature } \\
\left({ }^{\circ} \mathrm{C}\right)\end{array}$ & $\begin{array}{l}\text { Cooling } \\
\text { rate } \\
\left({ }^{\circ} \mathrm{C} / \mathrm{h}\right)\end{array}$ \\
\hline H-750 & $\mathbf{7 5 0}$ & 5 & 550 & 5 \\
H-780 & $\mathbf{7 8 0}$ & 5 & 550 & 5 \\
H-800 & $\mathbf{8 0 0}$ & 5 & 550 & 5 \\
H-820 & $\mathbf{8 2 0}$ & 5 & 550 & 5 \\
H-850 & $\mathbf{8 5 0}$ & 5 & 550 & 5 \\
Q-500 & 800 & 5 & $\mathbf{5 0 0}$ & 5 \\
Q-550 & 800 & 5 & $\mathbf{5 5 0}$ & 5 \\
Q-560 & 800 & 5 & $\mathbf{5 6 0}$ & 5 \\
Q-570 & 800 & 5 & $\mathbf{5 7 0}$ & 5 \\
Q-580 & 800 & 5 & $\mathbf{5 8 0}$ & 5 \\
C-4 & 800 & 5 & 550 & $\mathbf{4}$ \\
C-5 & 800 & 5 & 550 & $\mathbf{5}$ \\
C-6 & 800 & 5 & 550 & $\mathbf{6}$ \\
\hline Bold
\end{tabular}

Bold values indicate differences of the heat treatment processes

Lattice constants were determined from LeBail refinements. Microstructure and composition of the sample were analyzed using a field emission scanning electron microscope (FESEM) equipped with an energy dispersive X-ray analysis (EDX). Resistivity measurements were performed with a physical property measurement system (PPMS, Quantum Design).

\section{Results and discussions}

Figure 2a, c, e show the XRD data for all the samples. Most of XRD peaks correspond to (00L) reflections, (006), 
(0015), (0018), and (0021) distributed in the about $17.5^{\circ}$, $44.5^{\circ}, 54.5^{\circ}$, and $64.5^{\circ}$, respectively. Calculating the cell parameters of every sample based on each of the main peak of sample, we draw out the curve of cell parameters $c$ with temperature (see Fig. 2b, d, f). $\mathrm{Bi}_{2} \mathrm{Te}_{3}$ single crystal grows along the $c$-axis, so we only consider the value of the $c$. Figure $2 \mathrm{~b}, \mathrm{~d}$ show that the value of $c$ increases gradually with the highest temperature and the quenching temperature gradually; Fig. $2 \mathrm{f}$ shows that $c$ value decreases with the increase of cooling rate.
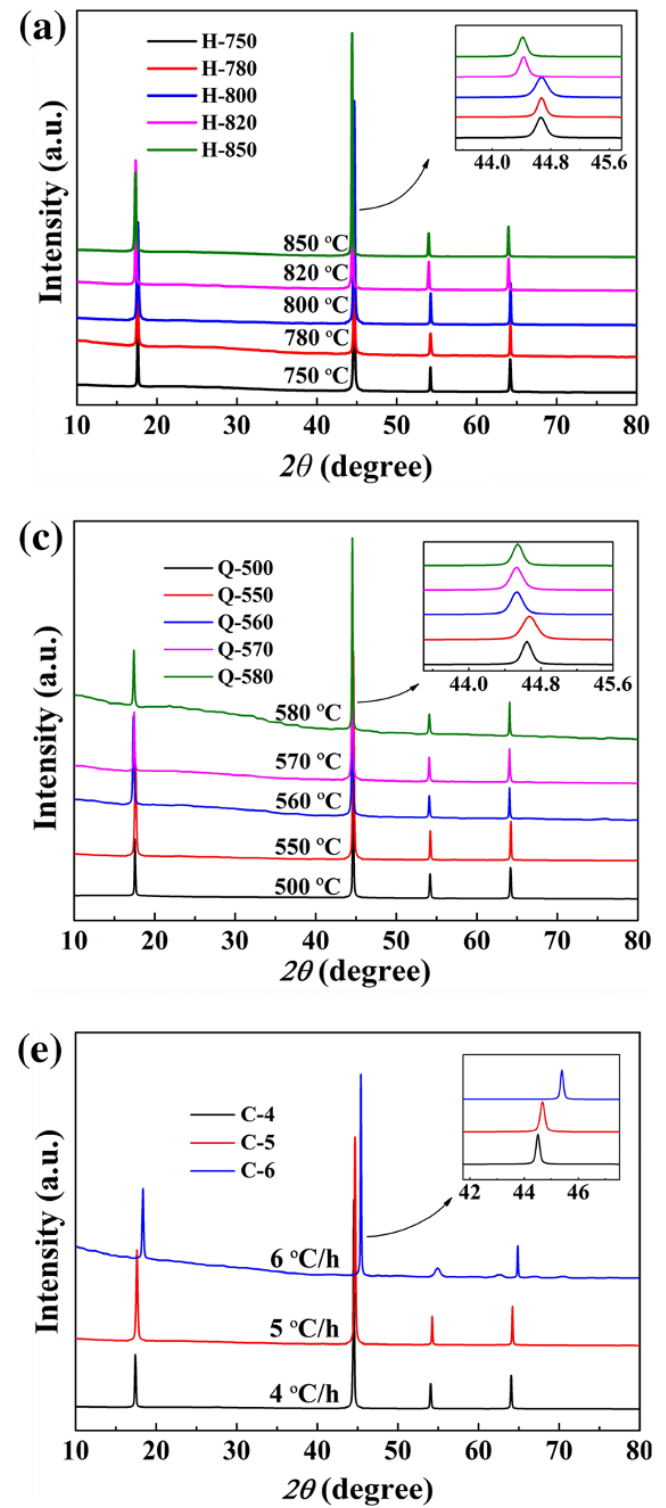

According to the standard PDF card, we can know that the $\mathrm{Bi}_{2} \mathrm{Te}_{3}$ lattice parameters are $a=b=4.3852$ and $c=30.4830 \AA$ [20]. In Fig. 2b, d, f, $c=30.48 \AA$ corresponds to the highest temperature $810^{\circ} \mathrm{C}$, quenching temperature $560{ }^{\circ} \mathrm{C}$, and the cooling rate $4.4^{\circ} \mathrm{C} / \mathrm{h}$.

We have got the sample of $\mathrm{Bi}_{2} \mathrm{Te}_{3}$ with the highest temperature $810{ }^{\circ} \mathrm{C}$, quenching temperature $560{ }^{\circ} \mathrm{C}$, and the cooling rate $4.4{ }^{\circ} \mathrm{C} / \mathrm{h}$. Figure 3 shows XRD pattern of the powder and single crystal as-grown samples $\mathrm{Bi}_{2} \mathrm{Te}_{3}$. After the $\mathrm{Bi}_{2} \mathrm{Te}_{3}$ standard pattern contrast, the vast majority
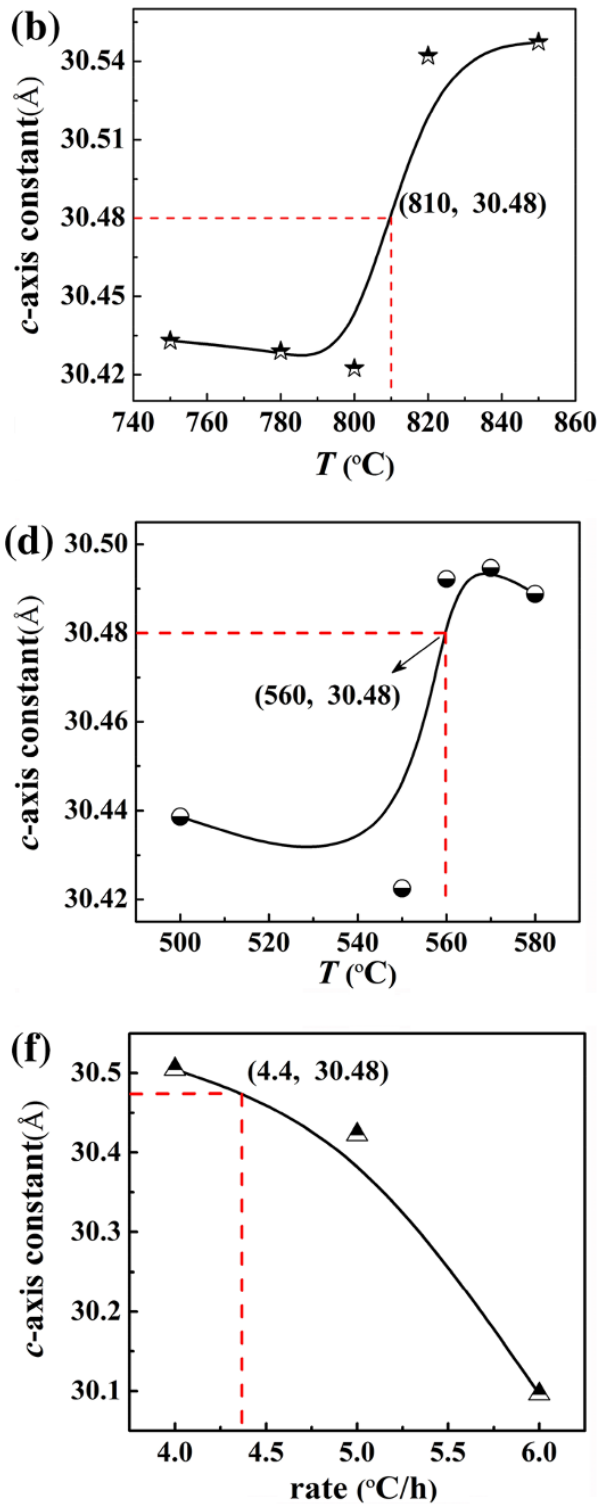

Fig. 2 X-ray diffraction curves of the H-750-H-850 (a), Q-500-Q-580 (c), and C-4-C-6 (e) and curves of cell parameters $c$ with the highest temperature (b), quenching temperature $(\mathbf{d})$, and cooling rate (f) 


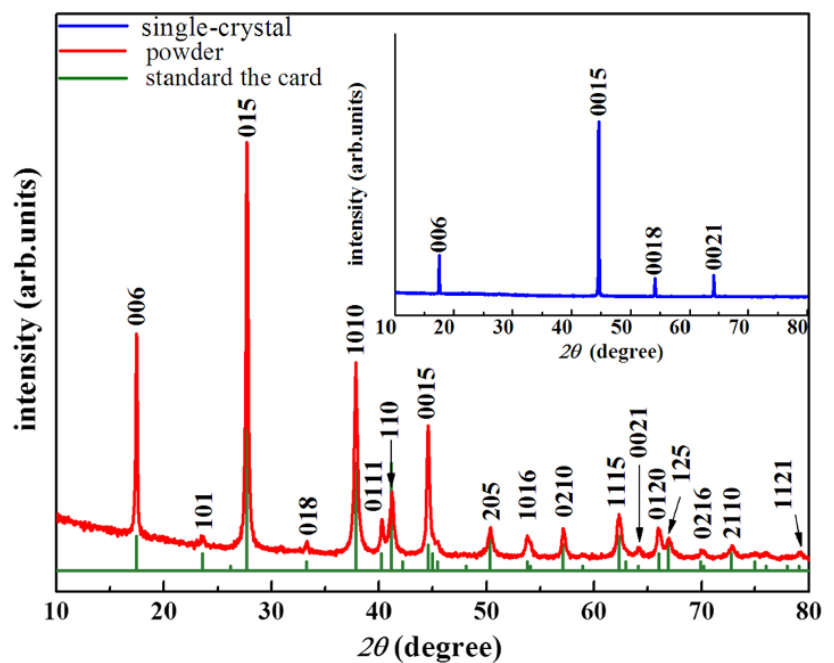

Fig. $3 \mathrm{Bi}_{2} \mathrm{Te}_{3}$ powder $\mathrm{X}$-ray diffraction pattern, inset is single crystal $\mathrm{X}$-ray diffraction pattern

Table 2 Five strong peaks value with its corresponding interplanar distance $d$

\begin{tabular}{llllll}
\hline Peak & 006 & 015 & 1,010 & 110 & 0,015 \\
\hline$d$ & 5.07422 & 3.22059 & 2.37772 & 2.19265 & 2.03361 \\
\hline
\end{tabular}

of the main peak marked in the picture can better match with standard pattern, indicating that the high-purity $\mathrm{Bi}_{2} \mathrm{Te}_{3}$ sample was obtained. The single-crystal sample only has $(00 L)$ peaks $(L$ is $3 n)$. It grows along the $c$-axis with the order of $\mathrm{Te}^{(1)}-\mathrm{Bi}-\mathrm{Te}^{(2)}-\mathrm{Bi}-\mathrm{Te}^{(1)}$ and crystallizes in the hexagonal system with space group of $\mathrm{R} / 3 \mathrm{~m}$. We calculated lattice parameters by taking the five strong peaks' interplanar distances $d$ (Table 2) from the XRD pattern of $\mathrm{Bi}_{2} \mathrm{Te}_{3}$ powder. The lattice parameters are $a=b=4.38456$ and $c=30.50063 \AA$, which are consistent basically with the standard PDF card $(a=b=4.3852$ and $c=30.4830 \AA$ ). However, the $c$ values of the samples H-800 and Q-550 are 30.42248 and $30.42369 \AA$, respectively, which have large difference with standard values.

It can be seen from Fig. 4a that the sample surface has a bright metallic luster; there is an obvious hierarchical structure, and the surface is relatively flat. Figure $4 \mathrm{~b}$ is EDX spectrum picture of $\mathrm{Bi}_{2} \mathrm{Te}_{3}, \mathrm{Bi}(\mathrm{L})$ and $\mathrm{Te}(\mathrm{M})$ in weight percentage of $52.82 \%$ and $47.18 \%$, and the atomic percentage of $40.61 \%$ and $59.39 \%$, respectively. In this sample, the atom ratio of $\mathrm{Bi}$ and $\mathrm{Te}$ was close to $2: 3, \mathrm{Bi}$ slightly excess. These results also deviated in component the stoichiometric ratio. It is consistent with the $\mathrm{Bi}-\mathrm{Te}$ alloy phase diagram.
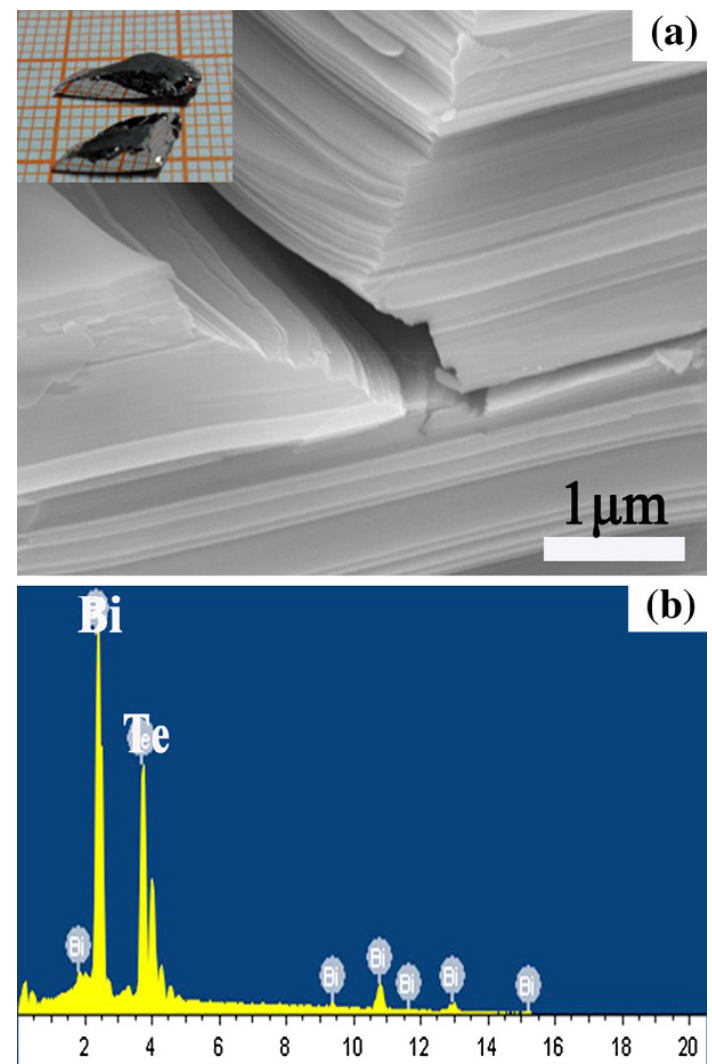

Fig. 4 SEM photographs of the single crystal of $\mathrm{Bi}_{2} \mathrm{Te}_{3}$ in 25,000 times and inset shows its physical picture. The conditions are that the highest temperature is $810^{\circ} \mathrm{C}$, quenching temperature is $560{ }^{\circ} \mathrm{C}$, and the cooling rate is $4.4^{\circ} \mathrm{C} / \mathrm{h}$ (a) and EDX spectrum picture of the $\mathrm{Bi}_{2} \mathrm{Te}_{3}$ single crystal (b)

Figure 5a shows the resistance dependence of temperature curve of the $\mathrm{Bi}_{2} \mathrm{Te}_{3}$ with the magnetic field parallel to the $c$-axis, and it can be seen that the sample shows metallic behavior over the whole temperature range. The values of resistances increase gradually with the temperature and the intensity of the applied magnetic field. The entire curves have the same variation trend. We did not observe any induced insulators conduction or abnormal behavior due to the additional magnetic field. The tiny fluctuation of the resistance is found near $50 \mathrm{~K}$. Figure $5 \mathrm{~b}$ is the curve of the resistances dependence of the magnetic field parallel to the $c$-axis at $T=5 \mathrm{~K}$. The values of resistances increase gradually with the applied magnetic field. At the high field, the curve of $R$ versus $H$ is linear. However, it deviates from the straight line at the part of the low filed. The linear variation law of the magnetic resistance may be associated with the surface state of TI. At low field the magnetic resistance deviates from the linearity, which may be associated with the weak anti-localization (WAL). 

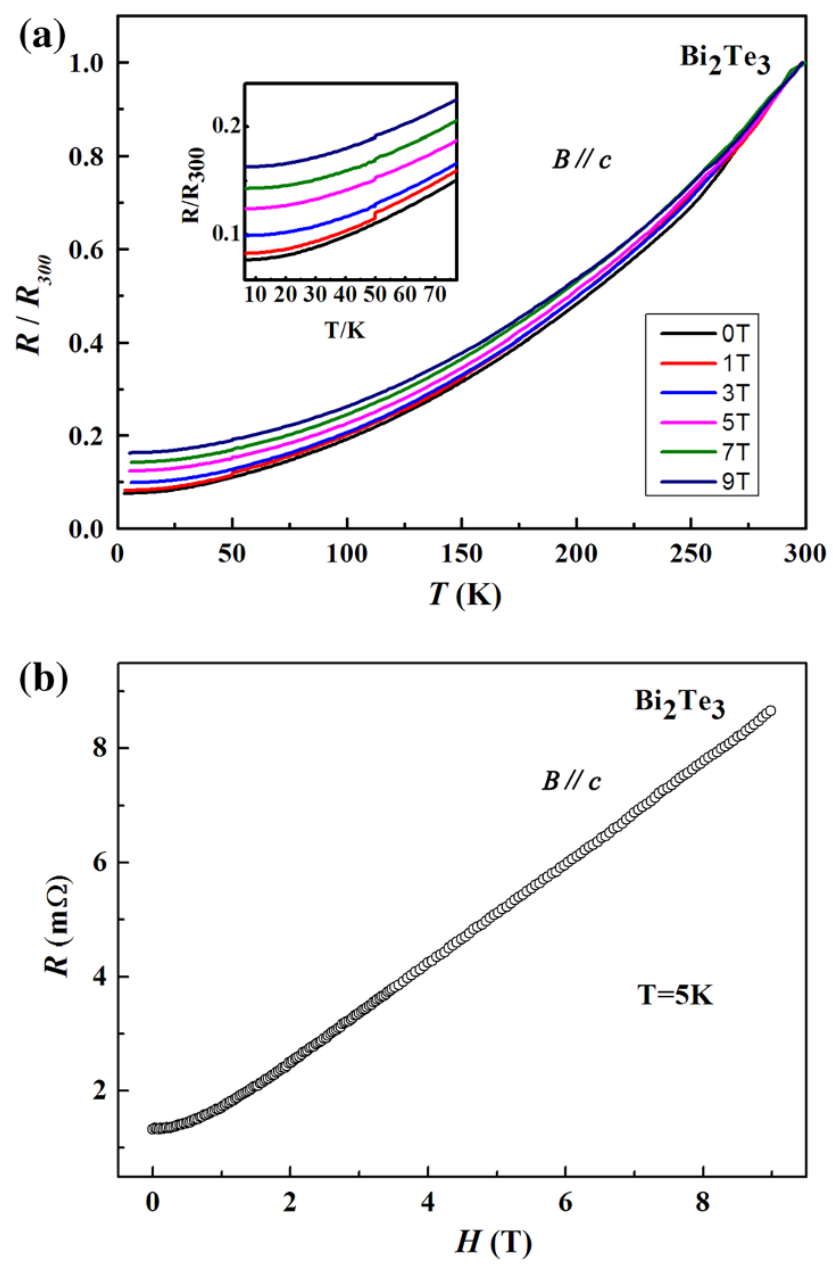

Fig. 5 a The $R-T$ curve $(0-9 \mathrm{~T})$ of the $\mathrm{Bi}_{2} \mathrm{Te}_{3}$. The resistances at $300 \mathrm{~K}$ are $0.14331,0.14224,0.14527,0.14495,0.14729$, and $0.14737 \Omega$, respectively. b The $R-H$ curve $(T=5 \mathrm{~K})$ of the $\mathrm{Bi}_{2} \mathrm{Te}_{3}$

\section{Conclusions}

We prepared the high-quality single-crystal synthesis of TI $\mathrm{Bi}_{2} \mathrm{Te}_{3}$ with the self-flux method. By controlling single variable and adjusting the parameters of heat treatment, we determined the optimal conditions for the highest temperature $810^{\circ} \mathrm{C}$, the quenching temperature $560^{\circ} \mathrm{C}$, and the cooling rate $4.4{ }^{\circ} \mathrm{C} / \mathrm{h} . \mathrm{Bi}_{2} \mathrm{Te}_{3}$ single crystal prepared under this condition has smooth surface with bright metallic luster and obvious layered structure, showing metallic behavior over the temperature range $7-300 \mathrm{~K}$. At low temperature, the resistance increases as additional magnetic field increase, and shows linear magnetic resistance behavior in the high field.

Acknowledgments This work was supported by the National Magnetic Confinement Fusion Science Program (Grant No. 2011GB112001), the Program of International S\&T Cooperation (Grant No. 2013DFA 51050), the National Natural Science Foundation of China (Grant No. 11104224, 11004162, 51271155), the Research Fund for the Doctoral Program of Higher Education of China (Grant No. 20110184120029 ), the
Fundamental Research Funds for the Central Universities (Grant No. 2682013ZT16, SWJTU11ZT31, 2682013CX004, SWJTU11BR063), and the Science Foundation of Sichuan Province (Grant No. 2011JY0031, 2011JY0130).

Open Access This article is distributed under the terms of the Creative Commons Attribution License which permits any use, distribution, and reproduction in any medium, provided the original author(s) and the source are credited.

\section{References}

1. Kane CL, Mele EJ (2005) $Z_{2}$ topological order and the quantum spin Hall effect. Phys Rev Lett 95:146802

2. Bernevig BA, Zhang SC (2006) Quantum spin Hall effect. Phys Rev Lett 96:106802

3. Qu DX, Hor YS, Cava RJ (2012) Quantum oscillations in magnetothermopower measurements of the topological insulator $\mathrm{Bi}_{2} \mathrm{Te}_{3}$. Phys Rev Lett 109:246602

4. Wang J, Chang CZ, Li HD et al (2012) Interplay between topological insulators and superconductors. Phys Rev B 85:045415

5. Bernevig BA, Hughes TL, Zhang SC (2006) Quantum spin Hall effect and topological phase transition in $\mathrm{HgTe}$ quantum wells. Science 314:1757

6. Kong DS, Chen YL, Cha JJ, Zhang QF et al (2011) Ambipolar field effect in the ternary topological insulator $\left(\mathrm{Bi}_{\mathrm{x}} \mathrm{Sb}_{1-\mathrm{x}}\right)_{2} \mathrm{Te}_{3}$ by composition tuning. Nat Nanotechnol 6:705-709

7. Scherrer H, Scherrer S (1996) In: Rowe DM (ed) Handbook of thermoelectrics. CRC Press, New York, pp 211-237

8. Hor YS, Richardella A, Roushan P et al (2009) P-type $\mathrm{Bi}_{2} \mathrm{Se}_{3}$ for topological insulator and low-temperature thermoelectric applications. Phys Rev B 79:195208

9. Qi XL, Hughes TL, Zhang SC (2008) Topological field theory of time-reversal invariant insulators. Phys Rev B 78:195424

10. Hsieh D, Qian D, Wray L et al (2008) A topological Dirac insulator in a quantum spin Hall phase. Nature 45:970-974

11. Zhang HJ, Liu CX, Qi XL et al (2009) Topological insulators in $\mathrm{Bi}_{2} \mathrm{Se}_{3}, \mathrm{Bi}_{2} \mathrm{Te}_{3}$ and $\mathrm{Sb}_{2} \mathrm{Te}_{3}$ with a single Dirac cone on the surface. Nat Phys 5:438-442

12. Chen YL, Analytis JG, Chu JH et al (2009) Experimental realization of a three-dimensional topological insulator $\mathrm{Bi}_{2} \mathrm{Te}_{3}$. Science 325:178-181

13. Hsieh D, Xia Y, Qian D et al (2009) Observation of timereversal-protected single-Dirac-cone topological-insulator states in $\mathrm{Bi}_{2} \mathrm{Te}_{3}$ and $\mathrm{Sb}_{2} \mathrm{Te}_{3}$. Phys Rev Lett 103:146401

14. Wang ZH, Qiu RLJ, Lee $\mathrm{CH}$ et al (2013) Ambipolar surface conduction in ternary topological insulator $\mathrm{Bi}_{2}\left(\mathrm{Te}_{1-\mathrm{x}} \mathrm{Se}_{\mathrm{x}}\right)_{3}$ nanoribbons. ACS Nano 7(3):2126-2131

15. Ni HL, Zhao XB (2007) Synthesization and properties of $\mathrm{Bi}_{2} \mathrm{Te}_{3}$ based nanocomposite thermoelectric materials. Zhejiang University

16. Kim TS, Kim IS, Kim TK et al (2002) Thermoelectric properties of p-type $25 \% \mathrm{Bi}_{2} \mathrm{Te}_{3}+75 \% \mathrm{Sb}_{2} \mathrm{Te}_{3}$ alloys manufactured by rapid solidification and hot pressing. Mater Sci Eng B 90:42-46

17. Keawprak N, Sun ZM, Hashimoto H et al (2005) Effect of sintering temperature on thermoelectric properties of pulse discharge sintered $\left(\mathrm{Bi}_{0.24} \mathrm{Sb}_{0.76}\right)(2) \mathrm{Te}_{3}$ alloy. J Alloy Compd 397:236-244

18. Seo J, Lee C, Park K (1998) Effect of extrusion temperature and dopant on thermoelectric properties for hot-extruded p-type Tedoped $\mathrm{Bi}_{0.5} \mathrm{Sb}_{1.5} \mathrm{Te}_{3}$ and n-type $\mathrm{SbI}_{3}$-doped $\mathrm{Bi}_{2} \mathrm{Te}_{2.85} \mathrm{Se}_{0.15}$. Mater Sci Eng B 54:135-140

19. Zhang HT, Luo XG, Wang CH et al (2004) Characterization of nanocrystalline bismuth telluride $\left(\mathrm{Bi}_{2} \mathrm{Te}_{3}\right)$ synthesized by a hydrothermal method. J Cryst Growth 265:558-562

20. National Bureau of Standards (US) Monograph 25 (1964) Sec 3, 16 